\title{
Experiencia y Transformación de la Percepción del Mundo en Pierre Hadot
}

\author{
Josemar de Campos Maciel* \\ Universidade Católica Dom Bosco - UCDB, Campo Grande, MS, Brasil \\ ORCID: https://orcid.org/0000-0001-8277-9422 \\ Marcio Bogaz Trevizan** \\ Universidade Católica Dom Bosco - UCDB, Campo Grande, MS, Brasil \\ ORCID: https://orcid.org/0000-0002-6839-788X
}

\begin{abstract}
RESUMEN
El texto presenta la génesis y la importancia del concepto de "Sentimiento Oceánico" en Pierre Hadot. Más allá de un conocido historiador de las ideas, Hadot posee una contribución filosófica fecunda, que se desborda entre la fenomenología y la filosofía histórica, en una visión práctica de la experiencia y de la actividad humanas. El núcleo de esta visión se inspira en una concepción particular de la relación entre el hombre y la realidad, que él desarrolla alrededor de una progresión de experiencias, refinando el concepto de "Sentimiento Oceánico", que toma prestado de otros autores. En este texto presentamos esa elaboración, que Hadot ejecuta hundiendo experiencia y reflexión. Aún, argumentamos que es de ahí que se erige su merecimiento de un hogar especial en la historia del siglo veinte: en espacio intersticial entre la historia y la experiencia, para hacer filosofía. En el primer momento de este texto partimos de escritos y entrevistas de Hadot para presentar la génesis de la noción de "Sentimiento Oceánico" en su obra. En seguida, planteamos en grandes rasgos la densidad del concepto, que sirve a la reflexión filosófica, y que además posee un gran potencial para el estudio de la experiencia humana.
\end{abstract}

Palabras clave: experiencia humana, sentimiento oceánico, Pierre Hadot.

\section{Experiência e Transformação da Percepção do Mundo em Pierre Hadot}

\section{RESUMO}

O texto apresenta a gênese e a importância do conceito de "Sentimento Oceânico" em Pierre Hadot. Além de ser um conhecido historiador das ideias, Hadot possui uma contribuição filosófica fecunda, que se desdobra entre a fenomenologia e a filosofia histórica, em uma visão prática da experiência e atividade humanas. O núcleo desta visão se inspira em uma concepção particular da relação entre homem e realidade, que ele elabora ao redor de uma progressão de experiências, refinando o conceito de "Sentimento Oceânico", que toma de empréstimo a outros autores. Neste texto apresentamos essa elaboração, em que Hadot entrelaça experiência e reflexão. Ainda, argumentamos que é daí que surge seu merecimento de um espaço especial na filosofia do século vinte: o espaço intersticial entre a história e a experiência, para o fazer intelectual e a reflexão filosófica. No primeiro momento do artigo, partimos de textos e entrevistas de Hadot para apresentar a gênese da noção de "Sentimento 
Oceânico" em sua obra. Em seguida, elaboramos grandes traços à densidade do conceito, que serve à reflexão filosófica e que, ademais, possui um grande potencial para o estudo da experiência humana.

Palavras-chave: experiência humana, sentimento oceânico, Pierre Hadot.

\title{
Experience and Transformation of World Perception in Pierre Hadot
}

\begin{abstract}
The text presents the genesis and importance of the concept of "Oceanic Feeling", based on Pierre Hadot. Beyond a well-known historian of ideas, Hadot is a consistent philosopher, holding the heritage of a contribution, which straddles between phenomenology and historical philosophy, in a practical vision of human experience and activity. The core of this vision is inspired by a particular conception of the relationship between man and reality, which he develops around a progression of experiences, refining the concept of "Oceanic Feeling", which he borrows from other authors. In this text we present that elaboration, which Hadot executes linking experience and reflection. Still, we argue that it is from there that one can support the merit of Hadot for a special place in the history of the twentieth century: in an interstitial space between history and experience, to do philosophy. In the first moment of this text we start from Hadot's writings and interviews to present the genesis of the notion of "Oceanic Feeling" in his work. Next, we outline in broad strokes the density of the concept, which serves philosophical reflection, and which also has great potential for the study of human experience.
\end{abstract}

Keywords: human experience, oceanic feeling, Pierre Hadot.

"Sentimiento oceánico" es un termo asumido por Pierre Hadot de los escritos de Romain Rolland que por su vez lo recibió de las memorias del místico indiano Sri Ramakrishna. Mesmo Freud contribuyó a la discusión del tema. Existe una discusión del tema para aclarar su valor cerca las relaciones con el misticismo hindu (Masson, 1980), con la lucha de Freud para superar sus prejuicios contra la religión (Parsons, 1999), pero hace falta estudiar el fenómeno en sí mismo, como se dibuja filosóficamente.

Esto lo ha logrado Hadot. Por eso, nos interesa proponer su discusión específica, cómo el tema se ha formado para él y presentar un planteo de su valor intelectual y filosófico. La expresión en si misma designa una experiencia de éxtasis, de trazos místicos, que sucede de forma repentina, no provocada y que lleva a la persona a una especie de conexión específica con el cosmos, con el mundo, en fin, con el Todo. Por tratarse de un acontecimiento excepcional en la vida del individuo, la experiencia oceánica, a menudo, es clasificada como 
"mística", o "mística salvaje" en la acepción de Hulin (1993). En este texto argumentaremos que Hadot va justamente más allá de esta percepción mística, aunque la asume y perfecciona.

Proponemos que sea la concepción de una nueva visión crítica, a que denominamos una percepción encantada de la plenitud de lo real. Esta plenitud aparece para Hadot, como el modo de ser de las cosas en cuanto tales - fuera de la mente del hombre e independientemente de ella, pero fascinante y llena de aspectos misteriosos en su inmanencia misma. Tal expresión está ligada a la noción del descubrimiento de una potencia en el hombre para abrazar la realidad con consciencia de sus propios límites.

El asunto es importante pues propone como foco de estudio la relación entre un concepto psicológico relatado a una experiencia mística, y su influencia en la formación de una escuela filosófica simpática a la mística, capaz de expandir ideas sobre el modo de vida de los intelectuales y de las personas comunes. Es decir, creemos que, entendiendo mejor la relevancia del sentimiento oceánico, se amplía el horizonte para el estudio de las relaciones entre la experiencia y su conceptualización para una teoría antropológica de horizonte más amplio. Resaltamos que ese esfuerzo de unir experiencia y sistemática conceptual encuentra en Pierre Hadot un especialista privilegiado que merece la atención que le intentamos dedicar.

La metodología utilizada será la de la investigación bibliográfica y documental. También analizaremos algunos textos de Hadot mediante un procedimiento hermenéutico simple, es decir, dejándonos guiar, cuando posible, por sus palabras mismas. Siendo así, nuestro trabajo adquiere un carácter expositivo y por eso busca atenerse a la letra y a la coherencia interna del pensamiento del autor, poniendo de manifiesto su densidad, más allá de su movimiento textual. En este movimiento específico, nuestro trabajo deja la descriptividad y gana tonos más interpretativos. Entre las obras del autor fueron utilizadas principalmente aquellas que se refieren al "sentimiento oceánico", y a otros conceptos que lo aclaran y desarrollan, tales como a la "filosofía como modo de vida" y a los "ejercicios espirituales".

\section{Pierre Hadot y la Experiencia Oceánica}

La forma en la que el filósofo francés Pierre Hadot (1922-2010) trabaja el concepto de Sentimiento Oceánico permite vislumbrar su densidad como filósofo, además de su ya conocida fuerza como historiador de la filosofía, crítico filológico y traductor. Así, nos toca discutir las experiencias místicas que Hadot tuvo en diversos momentos de su vida y que denominó "Sentimiento Oceánico" y también reflexionar sobre su proceso de maduración y de comprensión de la experiencia oceánica. 
En el libro-entrevista titulado La Philosophie comme manière de vivre, Hadot relata a los periodistas Jeannie Carlier y Arnold Davidson que en su adolescencia y en la vida adulta vivió diversas experiencias de deslumbramiento que marcaron profundamente su existencia. Según Hadot (2001), una de las más importantes experiencias le ocurrió en la calle, por la noche, mientras caminaba entre la casa de sus padres y el seminario menor (Petit Séminaire) hacia donde regresaba diariamente, mientras era seminarista sulpiciano. Así relata la experiencia: "Había caído la noche. Las estrellas brillaban en el cielo inmenso. En aquella época todavía podían verse. Otra vez fue en una habitación de nuestra casa” (Hadot, 2001, p. 23). Más adelante, narra que tuvo la misma sensación en otras ocasiones: "volví a tenerla, varias veces, por ejemplo, delante del lago mayor en Ascona o viendo la cadena de los Alpes, desde la orilla del lago Léman, en Lausana, o desde Salvan, en el Valais" (Hadot, 2001, p. 24). Con todo, en una entrevista al periodista Thierry Grillet, del semanario Le Nouvel Observateur, Hadot destacó que su primera experiencia oceánica le ocurrió cuando tenía 12 ó 13 años y por dos veces seguidas. Así lo relata:

Recuerdo especialmente lo que ocurrió en una noche de invierno cuando vi el cielo estrellado. De repente me sentí extraño y me sentí invadido por la angustia que era aterradora y deliciosa. Me sorprendió ser yo, estar allí en este mundo inmenso y desconocido del cual yo era parte (Hadot, 2008, pp. 23)

En todas las descripciones de las experiencias, Hadot plantea recibir una especie de visita del exterior y remarca que ellas equivalen a lo que Romain Rolland denominó "sentimiento oceánico".

Defenderé la expresión ‘sentimiento oceánico’ empleada por Romain Rolland y, por la misma razón, distinguiré esta experiencia de la de maravillarse ante la naturaleza que también he experimentado. Al hablar de 'sentimiento oceánico', Romain Rolland quiso expresar un matiz muy particular, la impresión de ser una ola en un océano sin límites, de ser una parte de una realidad misteriosa e infinita (Hadot, 2001, pp. 23)

Un elemento importante que considerar es que los "éxtasis" hadotianos parecen suceder cuando él se pone a contemplar el mundo, los entes en general y acontecen de forma repentina, sin previa manifestación ni contenidos esotéricos particulares. 
El cielo, las nubes, las estrellas, las 'noches del mundo, como me decía a mí mismo, me fascinaban. [...] Miraba hacia el cielo por la noche, y tenía la impresión de sumergirme en la inmensidad estrellada. Esta experiencia dominó toda mi vida (Hadot, 2001, pp. 24).

Como se puede deducir de las palabras de Hadot, lo que le sucedió fue una especie de arrebatamiento emocional, una suspensión de la racionalidad práctica, una expansión de la comprensión de la realidad hasta entonces no percibida. Fue verdaderamente un éxtasis en el cual él no decodificaba las cosas, solamente sentía las aterradoras y deliciosas manifestaciones del mundo desconocido. Fue como si estuviese invadido por el mundo, de tal forma que hubo una interacción entre él y el Todo.

El sentimiento oceánico aparece, así como una especie de viva interpelación del mundo al hombre. Casi una "llamada", que lleva a su interlocutor a romper la familiaridad con el mundo y a intentar comprender las realidades que están en él, pero que desafían los conceptos formulados hasta ocurrir la experiencia. Así, es una "llamada" porque es el mundo que en su inmensidad "convoca", "atrae"," "envuelve" y "seduce" a los que se abren a su presencia. Tal "llamada", es en la realidad la concreción de una atracción natural que existe entre el hombre y el Todo, pero que se realiza solamente en la vida de aquellos que están dispuestos a mirar más allá de lo ya percibido e intuido. Aquellos que atienden al "llamamiento" del mundo, lo hacen cuando se descubren como capax realitatis, es decir, en el momento en que se perciben capaces de coger la realidad como algo inmenso, incomprensible, demasiado extenso para ser absorbido por nuestro intelecto. Con todo, intuyen que ella puede ser investigada en profundidad y por eso se configura como una fuente inagotable de novedades.

Además, el "sentimiento oceánico" también puede ser entendido como una "llamada de la experiencia”, puesto que es la experiencia del hombre frente al mundo desconocido que le permite dejarse envolver por la densidad de la realidad. En otras palabras, la experiencia capta el mundo como "incomprensible" y la sensación del hombre se presenta como “invadido" por algo que le excede a él mismo. Entonces, también el sentimiento oceánico puede ser entendido como portavoz del exceso. Es decir, es él que permite al hombre la experiencia de la inabarcable realidad. Es "exceso" porque la realidad experimentada excede y pasa más allá de la medida que el hombre puede suportar sin entrar en estado de éxtasis. Por eso, en su biografía de Ramakrishna, Rolland reporta que él define el sentimiento oceánico como "una ola que le envolvió, invadió y casi le ahogó” (Rolland, 1945, p. 37-38). 
Es el movimiento del mundo en dirección al hombre y la acogida del hombre de una realidad que le supera.

Sin embargo, es importante subrayar que la experiencia oceánica no debe ser confundida con el "asombro", ya bastante documentado en la filosofía clásica, pues no se trata sólo de una experiencia que obliga a la reflexión sobre la armonía del cosmos. Más que eso, es un arrebatamiento, una invitación a salir de sí mismo e integrar la propia mirada acerca de la realidad, del ambiente, de la inmensidad, recapitulada en la voz "océano", más allá de una racionalidad sin cuerpo, en el sentido de una integración más profunda. En vez de reflexionar sobre la harmonía del cosmos, entonces, el hombre se ve tocado por el límite mismo.

Las condiciones en que sucedieron los referidos éxtasis no se alejan de la gramática ya expuesta en grandes líneas por Hulin (1993) en su descripción de la Mística Salvaje. En palabras simples: la persona está "sola", en "vagabundeo por el bosque", en "contemplación", etc. En otras palabras, las experiencias ocurren cuando la persona está relajada y totalmente desarmada de sus concepciones preestablecidas, de sus dogmas internos y entonces se encuentra sola con la naturaleza que le cerca.

Es importante decir que estar en "contacto con la naturaleza" no significa estar en medio de un bosque sino mucho más que eso. Significa encontrarse en actitud receptiva, lista para contemplar, mirar la belleza o la fealdad del paisaje. Significa tener la piel y no solamente los ojos listos para percibirse como parte integrante del cosmos y probar las sensaciones que emergen del contacto con toda la realidad que le cerca.

Un aspecto relevante que destacar es que el fenómeno se manifiesta justamente cuando se está libre del todo, cuando la persona está sola consigo misma y con el mundo que le cerca. Es decir, libre de las preocupaciones de la vida y despojada del 'yo' en el sentido que no está centrada en sí misma de manera egocéntrica. Es el momento en que uno está abierto a lo nuevo, al otro. En ese momento, o en ese estado, es posible transformar las sensaciones en reflexión más integrada, para más allá del tiránico racionalismo que entiende la relación con la naturaleza como una constante explotación, como una vía que sólo admite un movimiento que parte del hombre.

Así, al buscar explicaciones de la experiencia mística en los escritos de Hadot, el investigador descubre que él mismo afirma que no tiene condiciones de definir en qué consiste tal experiencia. Para él solamente es posible decir que "en todas partes la experiencia mística [...] aparece con las mismas características fundamentales: es indecible, aporta o bien una angustia, aunque deliciosa, o bien la felicidad del apaciguamiento. En general llega y se vuelve a ir súbitamente" (Hadot, 2001, p. 133). A partir de los comentarios hechos por Hadot 
es posible plantear que el sentimiento oceánico predispone a la persona a dar una especie de salto de calidad en la vida reflexiva dado que lleva al alargamiento de la consciencia y al reconocimiento de que hay una íntima relación entre la persona y el cosmos.

El sentimiento oceánico, como una modalidad de "expansión de la conciencia" puede ser interpretado desde la perspectiva hadotiana como una forma de iluminación interior, un despertar para las realidades no perceptibles en lo cotidiano pero que están ahí y no son captadas por las personas que no estén disponibles. Así, tal acontecimiento tampoco es necesariamente comprendido en profundidad e inmediatamente por la persona que vive la experiencia. La "experiencia" puede ser solamente el principio de la toma de conciencia de que pasó algo que modificará la manera de ver el mundo, a uno mismo, y que va siendo descubierta y entendida con el transcurrir de la vida.

Es posible decir que el "sentimiento oceánico" es la capacidad de captar parte de la realidad con los sentidos y con la intuición, es decir, mediante una expansión de las percepciones habituales. Es un acontecimiento que posibilita a la persona ver las cosas que nadie ve; de sentir, oír y oler lo que nadie puede sentir, oír y oler. Es una abertura emocional, psíquica e intelectual capaz de propiciar la comprensión de dimensiones desconocidas del Cosmos. Es la intuición de aspectos no perceptibles ordinariamente por el hombre. A este respecto, Hadot se refiere al filósofo Henri Bergson (1859-1941). Bergson fue premio Nobel de Literatura en 1927 y en sus escritos se interesó también por Espiritualidad y Mística, investigando experiencias inmediatas y la intuición. Sobre Bergson, Hadot afirma:

Bergson tuvo una influencia considerable en la evolución de mi pensamiento en la medida en que toda su filosofía se centra en la experiencia de un surgimiento de la existencia, de la vida, que experimentamos en nosotros en el querer y en la duración y que vemos, en la práctica, en el impulso que produce la evolución viva. Terminé la carrera de filosofía en 1939 y la disertación tenía por tema el comentario de esta frase de Bergson: 'La filosofía no es una construcción de Sistema sino la resolución tomada una vez mirado ingenuamente en sí y en torno a sí'. He explicado a menudo, quizá demasiado a menudo, el entusiasmo que experimenté al tratar este tema. Pero esto da testimonio del hecho de que aquél fue un acontecimiento considerable para mí. Esto muestra también que en 1939 los profesores de filosofía ya se plateaban el problema de la esencia de la filosofía (Hadot, 2001, pp. 29). 
Una obra de facto muy importante de Bergson que explora nuestro tema es su libro sobre "la energía espiritual" (Bergson, 2012). Es relativamente común decir que es un despertar de las facultades y que conduce a mirar más allá de las apariencias para entonces conocer la realidad de las cosas. Pero ¿qué provoca la experiencia oceánica?

A esta indagación es posible responder afirmando que son las condiciones personales de cada individuo, es decir, su grado de sensibilidad, las experiencias vividas y una finísima intuición que lo lleva a dimensiones nunca experimentadas. Una especie de prontitud, por el dolor o por la educación, según las narraciones de Hadot.

La experiencia oceánica es el resultado de la confrontación con lo indescriptible, con el Todo. Es un "ver sin esfuerzo"; es la inserción del hombre en una nueva atmósfera que lleva al individuo a percibir la pluralidad de las manifestaciones de un universo desconocido. En otras palabras, "lo que no se conoce, se presenta" y es interpretado como una realidad mística que invade al individuo, provoca el deslumbramiento y lo toma por entero, con la capacidad de generar ondas de reconfiguración de todo el perfil de su existencia.

En palabras de Hadot, se trata de algo bien más profundo que un simple deslumbramiento con la naturaleza; "lo que es capital es la impresión de inmersión, de dilatación del yo en Otro al que el yo no le es extraño ya que es una parte de él” (Hadot, 2001, p. 28-29). En este contexto es importante destacar que "los éxtasis místicos a veces son descritos en términos de voluptuosidad, en la cual, la pérdida del 'yo' puede volverse una confusión del 'yo' con el 'tú”” (Marra, 2001, p. 968). La existencia de "algo" que Hadot llama un Autre hace referencia a una realidad indescifrable que es el Todo, pero que algunas tradiciones religiosas creen que es un encuentro con la divinidad.

Sin embargo, también se puede considerar como un encuentro con una percepción más agudizada de la realidad, como es también evocado en algunos aspectos de la perspectiva filosófica y cosmológica del filósofo y también místico Pierre Teilhard de Chardin. En la década de 1950, en Europa, estaban en plena difusión sus textos, en los cuales postulaba una perspectiva evolucionista en la teología católica, asunto que mucho agradaba a Pierre Hadot. A ese respecto, él afirma que todo lo que le retenía en la iglesia era la idea "de una conciliación entre la evolución y el creacionismo" (Hadot, 2008a, p. 143); "El evolucionismo de Teilhard de Chardin y también el ecumenismo" (Hadot, 2001, p. 48). En este contexto, es perfectamente posible que las ideas de Chardin influyeran la visión hadotiana del mundo, y tal vez la comprensión de la experiencia oceánica, tanto que la condenación del modernismo y de algunas tesis de Teilhard contribuyeran a que Hadot abandonase la vida eclesiástica, en 1952 (Hadot, 2001). 
Por aquí habría una red de relaciones a explorar en biografías que plantean en experiencias como ésta la base de una conversión religiosa; o que plantean experiencias muy parecidas a la base de lo que hoy se denomina como "ecología profunda", como en las biografías de Arne Naess y de Aldo Leopold, Davi Kopenawa, Vandana Shiva. Mencionamos esa posibilidad sólo para registrar la fuerza del tema pues debemos atenernos a Hadot en su proceso de profundización.

\section{Pierre Hadot y el Proceso de Apropiación de la Experiencia Oceánica}

Al investigar la relevancia de la "experiencia oceánica" en la vida y pensamiento de Pierre Hadot es importante apuntar que él hizo públicos los relatos de sus éxtasis, pocos años antes de morir. Cuando era un joven profesor no reveló su experiencia al mundo académico, tal vez por desconocer el alcance de la importancia de aquel fenómeno en su vida o por miedo a no ser comprendido por sus compañeros de universidad. Así, es probable que no hablase de esta temática porque fue tomando conciencia gradual del impacto de esta con el pasar de su vida. Luego, solamente habló sobre ella cuando comprendió su real impacto en su experiencia académica.

Hay que procurar entender las circunstancias en las cuales Hadot se encontraba para poder especular a respecto de su silencio productivo - su actitud de no hablar de ninguna experiencia personal en virtud de no haberla comprendido o no haberla entendido en profundidad. Solamente con el tiempo, mucho tiempo de hecho, le ha sido posible entender lo que ha sido la experiencia y cómo ella influyó en sus actitudes y elecciones en la vida. En primer lugar es necesario destacar que en el período de 1945-1949, Hadot era un joven cura que comenzó a escribir una tesis en el Institut Catholique dedicada a la interpretación de los textos de Mario Victorino. Su opción por el referido filósofo fue una elección que evocaba parte de su voluntad de estudiar las cuestiones místicas. Así se expresa Hadot:

Finalmente me decidí por Victorino. Desde mi juventud sentía una atracción muy fuerte por la mística bajo todas sus formas, que me parecían que tenía que abrirme a la indecible experiencia de Dios. San Juan de la Cruz, pero también Plotino formaban parte de mis lecturas favoritas. Entonces, pensé unir mi trabajo universitario y mi interés por la mística (Hadot, 2001, pp. 44) 
En este momento de su vida, entre los años 1940 y 1950, los impactos de la experiencia oceánica parecen estar presentes, tanto que él se empeña en estudiar la mística. Sin embargo, no fue suficiente para que fuese explícitamente mencionada en sus investigaciones. Además, Hadot estaba totalmente envuelto por las concepciones eclesiásticas que no le permitían manifestar nada que no estuviera diligentemente de acuerdo con los dogmas católicos. A lo mejor no pensaba en revelar sus éxtasis oceánicos no solamente por miedo a la represión eclesiástica sino también por falta de abertura personal para comprenderse a sí mismo.

En aquel momento de su vida, en que la Iglesia vigilaba a todos los curas que no estaban estrictamente de acuerdo con sus doctrinas, si él hubiese hablado de experiencias de encuentro con el "Todo", estaría metido en un gran lío. Siendo así, el proceso de comprensión de sus experiencias oceánicas y la madurez para hablar de ellas se fueron desarrollando de forma lenta y gradual a partir de las opciones que fue tomando en el transcurrir de su trayectoria personal y espiritual.

Es posible que, en su vejez, después de largos años de maduración y de concreción del impacto de la experiencia oceánica en su vida, Hadot sintió que podría hablar sobre ellas. Además, la vejez ya le permitía hablar sin miedo de las vivencias que le fueron fundamentales, independientemente de la opinión de los demás. Gracias a tales relatos, les es posible a los estudiosos de su obra perseguir las huellas, los 'efectos', de la experiencia oceánica en su producción académica. Es decir, a pesar de que él no habla explícitamente de tal experiencia en períodos anteriores de su vida, es probable que la tuviese como telón de fondo en buena parte de sus investigaciones filosóficas, por lo menos en forma de categoría inspiradora y provocación crítica.

No obstante, es posible hallar una respuesta en el análisis de sus proprios textos a la pregunta "¿por qué Hadot no habló de sus experiencias oceánicas desde que ellas ocurrieron?". Según Hadot, la preocupación de mantener en secreto las experiencias místicas surgió en su adolescencia cuando comprendió que después de los éxtasis él se sentía aparte de los demás y no suponía que sus compañeros o incluso sus padres o "hermanos pudieran imaginar cosas de este género" (Hadot, 2001, p. 24). Según él, "fue solamente mucho más tarde" cuando descubrió que "muchas personas tienen experiencias análogas, pero no hablan de ellas" (Hadot, 2001, p. 24). En su caso habló, pero cuando ya era mayor.

Dada la novedad y complejidad de la experiencia, durante su adolescencia, momento en que ocurrieron los primeros éxtasis, Hadot no conseguía formular lo que sentía. Así, tenía la necesidad de escribir y en una primera tentativa de expresarse a sí mismo las sensaciones 
experimentadas redactó un pequeño ensayo. Según él, "era una especie de monólogo de Adán descubriendo su cuerpo y el mundo a su alrededor" (Hadot, 2001, pp. 23-24). Evidentemente, reflejaba las indagaciones de un chico católico adolescente que se sentía desafiado a comprenderse a sí mismo y una experiencia que no le era conocida.

A ese respecto, el propio Hadot destaca que en aquel periodo hizo anotaciones sobre sus vivencias que considera como "las primeras notas escritas que eran el eco del nacimiento de [su] personalidad" (Hadot, 2001, p. 23). Así, destaca que siempre se arrepentirá por haber tirado, por humildad cristiana, las referidas anotaciones. Según él, durante su vida de adulto, le resultó "muy difícil" reencontrarse "con el contenido psicológico de los conmovedores descubrimientos que [hizo] entonces" (Hadot, 2001, p. 24). Esto significa que en algunos momentos de su vida él recurría a los 'recuerdos oceánicos' oriundos de la experiencia con la intención de aprovecharlas para su confort espiritual y quizá para las reflexiones filosóficas. Según él, "en general, principalmente al comienzo, se me presentaron súbitamente, espontáneamente, sin ninguna preparación ascética o intelectual" (Hadot, 2001, p. 129). Así, después de que las experiencias espontaneas se acabasen, destaca que se esforzó en recuperar la conciencia de su existencia "como parte del universo para recuperar la intensidad de aquella experiencia” (Hadot, 2001, p. 129) y asegura que algunas veces la logró.

Hemos hablado de la experiencia oceánica, cuya portada y alcance ha tomado tiempo para Pierre Hadot. Planteamos que él fue lentamente tomando conciencia de la relevancia de las experiencias y de forma gradual fue percibiendo la influencia de ellas en su vida de filósofo. Además, dada la importancia de tales éxtasis en su vida, él los hizo públicos solamente después de su jubilación. Fue el período en el que la tranquilidad de la vejez le permitió hablar de ellos sin recelos. Por eso inferimos que esas experiencias fueron influyentes y fundamentales en toda su evolución personal como filósofo. Esta estructura, de la experiencia a la reflexión, no es reservada a la vida de Pierre Hadot. Por el contrario, ha informado también la vida de otras personalidades que, sensibles a "nuevos contextos", experimentan contacto con algo semejante a las experiencias oceánicas, que les permite observar nuevas configuraciones en la realidad. En general, sin hablar de experiencias oceánicas, ellas se lanzan a la búsqueda de nuevos recursos, es decir, de nuevas formas de expresión capaces de traducir experiencias que no se adecuan a los padrones intelectuales hasta entonces aceptables. Por eso, algo parecido al sentimiento oceánico puede estar en la base de diversos intelectuales no hegemónicos, es decir, que propusieron nuevos caminos de salida para la crisis del racionalismo occidental. 
Algunas de esas formas son constatables en las reflexiones de intelectuales contemporáneos a Hadot, como Arthur Schopenhauer (2007), Virginia Woolf (2015; 2017), Rainer Maria Rilke (1992), Romain Rolland (1929; 1930), Clarice Lispector (1998; 1999), Xavier Zubiri (1991; 2012), Héléne Cixous (1986), etc. Resumiendo, el tema de la experiencia oceánica se encuentra en el cruce entre la experiencia humana y su expresión como sistema o narrativa (ciencias, filosofía), o como simbolización (arte, religión).

Al considerar la importancia de la experiencia oceánica en el ámbito filosófico, en este cuadro, se puede ver que el pensamiento de Pierre Hadot hace parte del movimiento de renovación creativa del siglo XX que se concentraba en el intento de analizar la experiencia humana en el ámbito filosófico. Tal perspectiva trata de reconciliar "sistema" (matemáticas) y "flujo" (humanidades), "creatividad" y "tecnología", a partir de la intuición profunda de la capacidad humana de involucrarse con lo real, pero sin jamás agotarlo.

Siendo así, al considerar el sentimiento oceánico como un elemento de la experiencia humana, su consideración en el ámbito filosófico lleva a la conclusión de que el hombre es capaz de tocar realidades que superan la piel y la razón. Además, al tomar conciencia de tales experiencias, él puede sistematizar las intuiciones oriundas de tales experiencias y proponer caminos para que otros descubran la densidad de la realidad de forma racional y/o intuitiva.

Una ilustración puede ayudar a mostrar más claramente el punto. El pintor, al experimentar la densidad de la realidad, produce la obra de arte que le trasciende a él mismo y apunta a realidades hasta entonces no reconocidas. El poeta retrata lo indecible por medio de la redacción de sus poemas que en sí expresan lo que ni él mismo consigue expresar. A ese respecto menciona Rilke que:

Las cosas no son todas tan comprensibles ni tan fáciles de expresar como generalmente se nos quisiera hacer creer. La mayor parte de los acontecimientos son inexpresables; suceden dentro de un recinto que nunca oyó palabra alguna. Y más inexpresables que cualquier otra cosa son las obras de arte: seres llenos de misterio cuya vida, junto a la nuestra que pasa y muere, perdura (Rilke, 1992, pp. 7)

El filósofo intenta comprender lo que su lenguaje no logra explicar y por eso sus escritos, a veces, parecen incomprensibles. En cada escrito filosófico que nace de una vida consagrada a la experiencia se encuentra un "océano de indecible", de realidades que el lenguaje no consigue manifestar en su plenitud. Aquél que entiende la filosofía como un "modo de vida" inventa vivencias, ejercicios espirituales que llevan a sus interlocutores a 
experimentar elementos de la realidad que él vivió pero que en sí mismos son inexpresables. En este sentido, la práctica filosófica en Pierre Hadot, originaria de su vida de "místico y filósofo", se manifiesta como uno de los testimonios posibles de que el ser humano es capax realitatis. No obstante, al lado del artista y del poeta, que respetan su proprio dinamismo, el filósofo aparece como un "ciudadano cualificado" por la experiencia racional que lo capacita para decir las cosas respetando su fluidez.

\section{El Hombre, Capax Realitatis}

Como ya enunciamos anteriormente, el "Todo" trae consigo una densidad inabarcable que, en virtud de su natural incomprensibilidad, es perceptible como oceánica. Esta realidad desafía constantemente al filósofo y le pone ante el misterio. Desde esta perspectiva se puede decir que filosofar es sumergirse en lo oceánico. Es intentar entender lo que no es comprensible en su totalidad. Por eso, filosofar es de cierta forma tocar el misterio con "manos temblorosas" e intentar identificar lo que él dice sobre sí mismo. Sin embargo, el misterio no es lo divino sino solamente la realidad que en virtud de su densidad se manifiesta como exceso, como lo incomprensible que habita en todas las cosas. Así, "lo incomprensible", es solamente lo que no se puede conocer en virtud de su densidad. Tal realidad puede ser comparada con las grandes "fosas oceánicas" que están llenas de vitalidad y no pueden ser conocidas por los humanos en su totalidad, pero existen y están allí, aimentando todo el sistema de vida en el océano.

Sin embargo, lentamente el hombre puede investigar nuevos aspectos de la "fosa oceánica" e ir conociendo realidades deslumbrantes que no le eran accesibles. Así también ocurre con la "densidad del Todo". El filósofo va experimentando aspectos de la realidad otrora desconocida y entonces logra un conocimiento sobre sectores del Todo que antes no conocía. Sin embargo, "desde la perspectiva de la metáfora de los secretos de la naturaleza, se podría decir que abrir uno de esos secretos equivale a enfrentarse con un nuevo secreto que no hace más que esconder otro y así sucesivamente" (Hadot, 2004, pp. 243)

El proceso de abrir un secreto que contiene otro y así sucesivamente lleva a intuir que el hombre es capax realitatis pues busca de forma incansable resolver lo que se presenta ante él. La idea es acá presentada como una paráfrasis de la expresión homo capax Dei, de los padres de la Iglesia (Spencer, 2018), de la cual sería una especie de naturalización en paralelo. Es decir, afirmaremos que, en Hadot, viene enunciada la capacidad del hombre de conocer aspectos de la totalidad de lo real, no solamente las apariencias de las cosas. Mas ese 
conocimiento no es todo explicito, ni todo claro, pero mesmo así tiene una función muy específica: preservar el horizonte de conocimiento; preservar el deseo de progredir conociendo; preservar las virtualidades. Es la idea que expresa la capacidad del hombre de adentrar en la densidad de la realidad y emitir juicios sobre la parte con la cual interactuó, pero teniendo en mente una impresión de la importancia de todo el contexto, por el cual ha sido tocado. En cuanto al termino Realitas, debe ser entendido en su sentido propio y específico, es decir, existiendo independientemente de la mente humana.

Decir que el hombre es Capax significa afirmar una potencia; que él tiene medios de conocer aspectos de la totalidad de lo real de tal modo que emite juicios sobre parte de la realidad. Decimos aspectos porque la densidad de la realidad es infinitamente superior a la capacidad de conocimiento del hombre. Así, cuando algunos hombres se encuentran con la dicha "densidad de la realidad" mediante una experiencia mística se sienten envueltos por el misterio dado que no consiguen decodificar lo que su intelecto percibió. Esto es lo oceánico, lo inabarcable pero real, material e inconcebible. Cuando ocurre la interacción del sujeto con la "totalidad de lo real" se produce un cambio de significado de lo que era lo real para él. Es decir, para el sujeto afectado se vislumbra "una nueva forma de ser, de pensar, de sentir, de ver, por ende, una nueva forma de concebir el mundo y de concebirnos como seres en el mundo" (Hernandez, 2003, p. 33).

\section{Consideraciones Conclusivas}

En el presente texto discutimos algunas consecuencias de la experiencia oceánica en la vida de Pierre Hadot, y algo de su valor filosófico. Al analizar los relatos sobre lo sucedido, se observa que aquellos éxtasis cambiaron su manera de mirar la realidad y le provocaron la “conciencia de sí mismo en el mundo". De modo particular Hadot afirma que su vocación filosófica tuvo su origen en los éxtasis oceánicos. Además, destaca que aquellas experiencias determinaron su concepción de filosofía que él concibió como una transformación de la percepción del mundo.

Sin embargo, lo que Hadot vivió no fue una realidad provocada, sino que fue un verdadero éxtasis que le tomó por asalto. Fue una experiencia sensible que rebasó las ideas, pero no las abandonó. Es decir, por tratarse de una experiencia, el sentimiento oceánico produce vivencias que están más allá de las ideas preconcebidas, pero no suprime la posibilidad de comprensión de lo vivido. Además, él es del orden de las experiencias 
fundamentales que en vez de ser producidas por seres humanos producen configuraciones en la vida de humanos, los toman al asalto.

De forma objetiva, se puede decir que el sentimiento oceánico está ligado a la sensibilidad y se presenta como una experiencia que invade lo cotidiano y transforma la manera de ver el mundo de quien la vive. Tal experiencia recuerda que el hombre tiene capacidad de conocer aspectos de la densidad de la realidad que están más allá de la percepción propuesta por la racionalidad moderna. No obstante, él es de orden natural, no sobrenatural, es inmanente y se presenta como una forma de manifestación de la densidad de la realidad. Así, se configura como misterio dado que pone a la persona en contacto con dimensiones de la realidad que ella desconoce. Es decir, para el sujeto afectado se vislumbra "una nueva forma de ser, de pensar, de sentir, de ver, por ende, una nueva forma de concebir el mundo y de concebirnos como seres en el mundo" (Hernandez, 2003, p. 33).

\section{Referencias}

Bergson, H. (2012). La energía espiritual. Buenos Aires: Editorial Cactus.

Cixous, H. (1986). Entre l'écriture. París: Des Femmes.

Hadot, P. (1977). Exercices Spirituels et philosophie Antique. Annuaire de la V Section de l'École pratique des hautes études, 84, 25-70.

Hadot, P. (2001). La Philosophie comme manière de vivre: Entretiens avec Jeannie Carlier et Arnold I. Davidson. París: Édicions Albin Michel S. A.

Hadot, P. (2004). Le voile d'Isis: Essai sur l'histoire de l'idée de Nature. París: Gallimard.

Hadot, P. (2008, Julliet 10). Mes exercices spirituels, par Pierre Hadot. Bibliobs. Recuperado de https://next.liberation.fr/livres/2004/04/08/hadot-le-mystique-sauvage_475318

Hadot, P. (2008a). Pierre Hadot: Face au ciel étoilé, j’ai vraiment éprouvé le sentiment brut de mon existence. Philosophie Maganize, (21), 52-57. Recuperado de http://www.philomag.com/les-idees/entretiens/pierre-hadot-face-au-ciel-etoile-jaivraiment-eprouve-le-sentiment-brut-de-mon

Hernández, C. T. (2003). El significado del concepto de lo real. Acta Universitaria, 13(supl.), 30-34. Recuperado de http://www.redalyc.org/articulo.oa?id=41609808

Hulin, M. (1993). La Mystique sauvage: Aux antipodes de l'esprit. París: P.U.F.

Lispector, C. (1998). Perto do Coração Selvagem. São Paulo: Rocco.

Lispector, C. (1999). A Maçã no Escuro. São Paulo: Rocco. 
Marra, B. (2001). Sexualidade. In. Borriello, L. et al. (Orgs.), Dicionário de Mística. São Paulo: Paulus, Loyola.

Masson, J. M. (1980). The Oceanic Feeling: The origins of religious sentiment in ancient India. Dordrecht, Holland: D. Reidel Publishing Co.

Parsons, W. B. (1999). The enigma of the Oceanic Feeling: Revisioning the psychoanalytic theory of mysticism. New York: Oxford University Press.

Rilke, R. M. (1992). Sonette an Orpheus. New York: W.W. Norton \& Co.

Rolland, R. (1929). La Vie de Ramakrishna. Paris: Stock.

Rolland, R. (1930). La Vie de Vivekananda et l'Evangile Universel. Paris: Stock.

Rolland, R. (1945). Vida de Vivekananda. Buenos Aires: Editorial Kier.

Schopenhauer, A. (2007). Die Welt als Wille und Vorstellung. Zürich: Diogenes.

Spencer, M. K. (2018). Perceiving the Image of God in the Whole Human Person. The Saint Anselm Journal, 13(2), 1-18. Recuperado de https://www.anselm.edu/sites/default/files/Documents/Institute\%20of\%20SA\%20Stud ies/Perceiving\%20the\%20Image\%20of\%20God-

Final\%20Draft\%20for\%20St\%20Anselm\%20Journal.pdf . Fecha de visualización el 02/06/2020.

Woolf, V. (2015). Mrs. Dalloway. London: Alma Classics.

Woolf, V. (2017). To the Lighthouse. London: Alma Classics.

Zubiri, X. (1991). Inteligencia Senciente. Madrid: Editorial Alianza.

Zubiri, X. (2012). Hombre y Dios. Madrid: Editorial Alianza.

Endereço para correspondência

Josemar de Campos Maciel

Rua Abraão Bacach, 88 casa 10, Santa Luzia, Campo Grande - MS, Brasil. CEP 79116-605

Endereço eletrônico: maciel50334@yahoo.com.br

Marcio Bogaz Trevizan

Rua 14 de julho, 4466 ap. 1502 Torre 1, Campo Grande - MS, Brasil. CEP 79010-470

Endereço eletrônico: trevizan.marciob@gmail.com

Recebido em: 04/07/2020

Aceito em: 06/09/2020 


\section{Notas}

* Mestre em Psicologia (1999) pela Universidade Católica Dom Bosco; Doutor em Psicologia (2004) pela Pontifícia Universidade Católica de Campinas, SP.

** Mestre em Educação (2011, Universidade Federal da Grande Dourados); Doutor em Filosofia (2020, Pontifícia Universidade Católica de Buenos Aires, AR).

Este artigo de revista Estudos e Pesquisas em Psicologia é licenciado sob uma Licença Creative Commons Atribuição-Não Comercial 3.0 Não Adaptada. 